\title{
LINGUAGENS (a) indice \\ EDUCAÇÃO, CULTURA, TRABALHO E CIDADANIA: UMA RELAÇÃO NECESSÁRIA NO ENSINO EM CONTEXTOS RURAIS
}

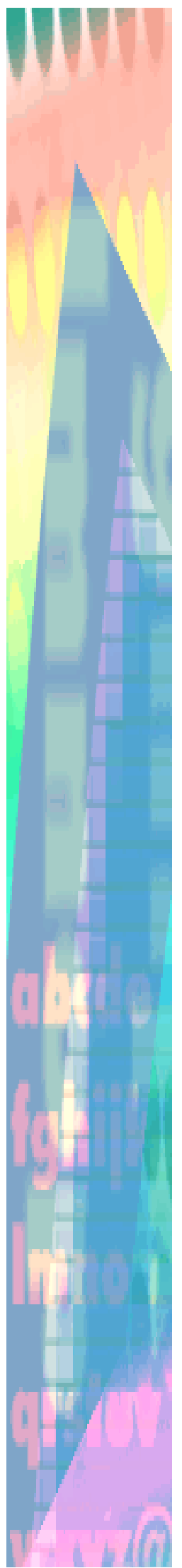

Irene Fernandes dos Santos

\section{INTRODUÇÃO}

O fenômeno da globalização, ao interferir em todas as áreas da vida contemporânea, tende a homogeneizar comportamentos, descaracterizando em grande parte os elementos constitutivos de determinados contextos sociais. Ao mesmo tempo, porém, detecta-se neste final de milênio, como uma forma de enfrentamento a esse processo de massificação e de descaracterização cultural, uma tendência para o fortalecimento identitário dos sujeitos e dos microcosmos socioculturais. Assim, movimentos voltados para o resgate da história e da cultura de pequenas comunidades regionais e locais se revitalizam, dando margem ao surgimento de diversas iniciativas, muitas delas levadas a efeito por instituições educacionais situadas em áreas de culturas específicas.

Esse é o caso de muitas escolas rurais, cujos educadores dão-se conta da necessidade de redimensionar seus projetos pedagógicos tendo em vista possibilitar aos educandos uma visão mais crítica e uma postura verdadeiramente cidadã, para enfrentar as novas contingências da vida social. Tais preocupações e propósitos têm motivado os trabalhos do Grupo de Estudos e Pesquisas "Contexto e Interdisciplinaridade no Ensino Rural"- GEPCIER, integrando professores de sete escolas-núcleo rurais de Dilermando de Aguiar e de Santa Maria - RS / Brasil. Essas escolas aglutinam cerca de 1170 crianças e jovens oriundos de 73 pequenas localidades rurais, algumas delas situadas em áreas de forte influência da imigração italiana (distritos de Palma e de Santa Flora, por exemplo). Em outras, sobretudo as situadas nos distritos de São José da Porteirinha, Boca do Monte, Pains e São Valentim, ocorre a presença de elementos típicos da cultura tradicional gaúcha, estando situadas em antigas zonas de transição entre núcleos de colonização lusa e hispânica.

O presente trabalho apresenta, de forma sucinta, resultados parciais de alguns estudos, pesquisas e/ou práticas pedagógicas contextualizadas e interdisciplinares, que os participantes do GEPCIER realizam, no sentido de uma melhor percepção das relações subjacentes neste contexto e para melhor situarem-se frente aos efeitos contraditórios da globalização social, econômica e cultural no meio onde atuam. Os trabalhos foram estruturados a partir dos pressupostos teórico-metodológicos que fundamentam as atividades do grupo e que são os seguintes: 1) Resgate ético, histórico e cultural das comunidades envolvidas; 2) Articulação do saber escolar com as atividades produtivas e com o contexto sociocultural; 3) Ênfase aos processos participativos e ao desenvolvimento da linguagem para o fortalecimento da identidade e a construção da cidadania dos sujeitos rurais.

\section{RESGATE ÉtICO, HISTÓRICO E CULTURAL DAS COMUNIDADES ENVOLVIDAS}

Entende-se a cultura como o conjunto das manifestações e ações humanas que se expressam e materializam num determinado espaço e tempo histórico e que, mesmo 
em contínuo processo de interação com outros contextos, singularizam os diferentes grupos sociais.

À luz desse entendimento, reconhece-se a necessidade da escola rural, em sua prática educativa, estabelecer profunda conexão com a comunidade que a abriga, descobrindo nela seu potencial para a produção de um conhecimento contextualizado e interdisciplinar e para o cultivo de valores necessários à formação de um sujeitocidadão. Concorda-se, nesse sentido, com Speyer quando ressalta a importância dessa conexão, afirmando que:

É, pois, sem dúvida, no meio rural que vamos encontrar os valores primitivos da cultura popular do povo brasileiro; é a partir desses valores que devemos construir nossos parâmetros educacionais para esse meio; e é somente se o levarmos em conta como "raízes" que podemos cultivá-los e fazer com que frutifiquem. (SPEYER, 1983:47).

No plano das pesquisas sócio-históricas em desenvolvimento pelo GEPCIER, destaca-se o trabalho realizado pela Profa Vânia F. Rocha, da E. M. José Paim de Oliveira, intitulado "Leitura sócio-histórica e cultural de uma comunidade rural". A pesquisa consistiu, primeiramente, no levantamento de dados, através de visitas junto às famílias de antigos moradores do distrito de São Valentim, onde se situa essa escola. Foram entrevistadas pessoas que vivem na região há mais de cinco décadas e que forneceram significativas informações sobre as condições de vida de antigamente, mudanças verificadas no espaço físico, formas de trabalho e de organização social, crenças religiosas, atividades econômicas e de lazer, meios de transporte e de comunicação, etc. O tratamento pedagógico interdisciplinar dado ao material coletado tem como base teórica "a leitura de mundo" preconizada por Paulo Freire, ensejando o fortalecimento da identidade cultural do educando e da própria comunidade, valorizados em seus costumes e protagonistas de sua história.

Um outro trabalho de resgate da história e da cultura local está sendo desenvolvido na E.M. Major Tancredo Penna de Moraes, da qual participam do GEPCIER, as Prof $^{\text {as }}$ Terezinha Balconi e Sirlei Maria K. Wagner. Essa escola situa-se no distrito de Palma, cuja origem está ligada à colonização italiana, pertencendo à região da $4^{a}$ Colônia sediada em Silveira Martins. Para esse estudo, os professores-pesquisadores apóiam-se em SANTIN \& ISAIA (1990). Afirmando que "é no passado que encontramos os estratos essenciais de nossa identidade, seja individual, seja grupal", esses autores incentivam a realização dessa pesquisa escolar, cuja importância social está, sobretudo, no fato de valorizar o homem enquanto sujeito histórico e despertar nos educandos a consciência de sua condição no mundo.

\section{ARTICULAÇÃO DO SABER ESCOLAR ÀS ATIVIDADES PRODUTIVAS E AO CONTEXTO SOCIO-CULTURAL.}

A partir de uma visão não mais dicotômica do urbano e do rural, mas na ótica de um continuum urbano-rural, o Prof. Roberto Boemo, da E. M. Santa Flora, integrante do GEPCIER, preocupa-se em apontar elementos que caracterizam um processo de urbanização que tem alterado significativamente o modo de ser, de pensar e de agir de grande parte das pessoas (sobretudo as mais jovens) das localidades-sedes dos distritos pesquisados (Santa Flora e de Arroio Grande). Em seu trabalho, sob o título "O novo perfil da sociedade rural face à globalização econômica e cultural", o professor-pesquisador constata que as novas exigências científicas e tecnológicas que se apresentam aos pequenos e médios produtores rurais inviabiliza as atividades agrícolas e pastoris nos moldes tradicionais. Alerta os educadores para a urgência da adequação dos currículos escolares e dos discursos pedagógicos a esse novo contexto, tendo em vista a formação de novas mentalidades, para fazer frente a essa complexa problemática.

Ainda, nesse sentido, destacam-se várias práticas interdisciplinares que já foram 
apresentadas e discutidas pelos participantes do GEPCIER na oficina organizada no evento Novas Propostas - 12a edição, em agosto de 1999, no CAL-UFSM. Uma delas, intitulada "Matemática e Geografia: uma alternativa de leitura do meio rural", foi

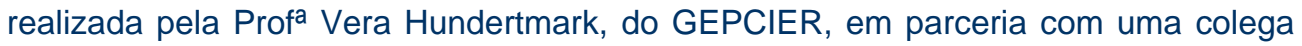
de sua escola (E.M. Valentim Bastianello), envolvendo os conteúdos de monômios e polinômios. Nesse trabalho foram relacionados assuntos referentes à produção agropecuária e à preservação ambiental, sendo também discutidas outras questões ligadas ao espaço geográfico local, regional e nacional. Nessa atividade foram valorizadas as experiências individuais e a interpretação do meio através do uso de diferentes formas de linguagens, despertando o interesse do aluno e facilitando a compreensão de conhecimentos específicos das disciplinas envolvidas no trabalho.

Ainda nesta escola, desenvolve-se um projeto interdisciplinar envolvendo todos os professores, coordenados pela sua diretora Edinara Moura e a coordenadora pedagógica Eliana Rocha, também membros do GEPCIER. Enfocando o tema "Comidas do Brasil", o trabalho propõe o estudo dos alimentos, valorizando a cultura das diversas regiões do país, o resgate dos costumes regionais e locais, incentivando a produção de gêneros alimentícios, observando o valor nutricional de cada um e a busca de hábitos alimentares saudáveis. Envolve pesquisa, estudos de caso e trabalhos práticos em todas as disciplinas do currículo.

A professora Liane Pötter, da única escola unidocente integrante do GEPCIER, realiza, com sua turma de $1^{\mathrm{a}}$ a $4^{\mathrm{a}}$ séries, atividades integradas que fogem da rotina de uma escola tradicional. Preocupada em melhorar a qualidade de vida de seus educandos, essa professora faz com que a unidocência torne a escola mais parecida com a vida que a penetra e lhe fornece elementos para a interligação de conteúdos e vivência de valores. A heterogeneidade do grupo amplia e fortalece laços, permitindo que a criança, em conjunto com seus colegas, vá resolvendo problemas do dia-a-dia e torne-se protagonista de seu conhecimento e da sua história.

\section{4. ÊNFASE AOS PROCESSOS PARTICIPATIVOS E AO DESENVOLVIMENTO DA LINGUAGEM PARA O FORTALECIMENTO DA IDENTIDADE E A CONSTRUÇÃO DA CIDADANIA DOS SUJEITOS RURAIS.}

Apoiada em Vygotsky, Freitas refere-se à linguagem como:

... um fator importante para o desenvolvimento mental de uma criança, exercendo uma função organizadora e planejadora de seu pensamento, ela tem também uma função social e comunicativa. Através da linguagem a criança entra em contato com o conhecimento humano e adquire conceitos sobre o mundo que a rodeia, apropriandose da experiência acumulada pelo gênero humano no decurso da história social. É também a partir da interação social, da qual a linguagem é a expressão fundamental, que a criança constrói sua própria identidade. (FREITAS,1995:98) .

Com base nessa concepção vygotskyana da linguagem, o GEPCIER desenvolve reflexões teóricas que possam embasar a realização de uma prática pedagógica que valorize o desenvolvimento das diferentes linguagens presentes na cultura rural, tomando-as a um só tempo mecanismos de preservação ético-cultural, fortalecimento da identidade e transformação social. Acredita-se, desse modo, que a cidadania dos sujeitos rurais pressupõe uma autonomia discursiva que os fortaleça no seu necessário diálogo com o mundo urbano.

Nesse sentido, a coordenadora do GEPCIER propôs um trabalho que visa explicitar os tipos de linguagem presentes na sociedade rural, na área abrangida pelo projeto, analisando sua forma de tratamento no currículo escolar, de modo a poder resgatar seu papel identitário, cultural e construtor da cidadania. Trata-se de uma pesquisa ainda em fase inicial, mas que já conta com a contribuição de outros estudos e atividades realizados e que vêm ao encontro do objetivo dessa pesquisa.

Um desses estudos foi desenvolvido pelas Profas Luciana M. Stangherlin e Rosimeri 
M. de Oliveira, da E.M. Bernardino Fernandes, salientando a importância da leitura e da escrita em todas as disciplinas como fundamento para a apropriação do conhecimento e para a participação social. A contextualidade, a intertextualidade e a ludicidade são destacadas como elementos desencadeadores do gosto pela leitura e da produção textual do aluno.

A Profa Denise Dorneles da Silva buscou na linguagem cênica uma forma de conduzir interdisciplinarmente o ensino da História aos seus alunos de $5^{\mathrm{a}}$ a $8^{\mathrm{a}}$ séries da $\mathrm{E}$. Valentim Bastianello. Através da montagem de uma peça teatral intitulada "Vozes do Túnel", cujo tema central são os preconceitos que perpassam o cotidiano social, está sendo possível, segundo a referida professora, formar identidades reflexivas e autônomas, valorizar os educandos, possibilitando-lhes expressarem-se de forma artística, oral, gestual e corporal, rompendo arquétipos sócio-históricos e culturais, desconstruindo e ressignificando o mundo das imagens e desenvolvendo a criatividade e a criticidade.

Ainda campo da linguagem artística, a Profa Nadia P. dos Santos, da E.E. Almiro Beltrame, realiza um trabalho de pesquisa-ação, propondo-se a desenvolver a linguagem e a cidadania de seus educandos, com enfoque na educação ambiental, através das artes plásticas. Seu trabalho consiste basicamente no aproveitamento de resíduos sólidos encontrados no ambiente na confecção de jogos e brinquedos. Facilitando a expressão artística do educando, a coordenação motora, o equilíbrio, desenvolve o potencial criativo o lúdico e o social do educando.

Em todos esses trabalhos, percebe-se a vontade dos professores-pesquisadores de ampliarem seus conhecimentos através da investigação teórica aplicada à prática docente. Conscientes de seu papel mediador do conhecimento e transformador da realidade e profundamente imbuídos de seu compromisso social, os integrantes do GEPCIER buscam, individual e coletivamente, a construção de uma proposta de currículo condizente com as exigências de um mundo em acelerado processo de transformações e cujos reflexos no mundo rural provocam impactos com efeitos aos quais a população nem sempre está suficientemente preparada.

\section{BIBLIOGRAFIA:}

FREIRE, Paulo. A importância do ato de ler. São Paulo, Cortez Editora, 1986.

FREITAS, Maria Tereza C. Vygotsky \& Bakhtin Psicologia e Educação: um intertexto. São Paulo: Editora Ática, 1995.

SPEYER (1983), Anne Marie. Educação e Campesinato: Uma educação para o homem do meio rural. São Paulo: Ed. Loyola, 1983.

UNIVERSIDADE FEDERAL DE SANTA MARIA, PREX-CAL. 12ª Edição Seminário Novas Propostas. Códigos e Linguagens. Caderno de Resumos. Santa Maria: UFSM, Ago/1999.

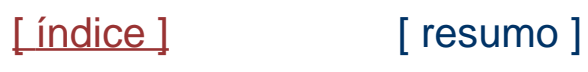

